\title{
Toward Extraplanetary Under-Ice Exploration: Robotic Steps in the Arctic
}

Clayton Kunz ${ }^{\star}$, Chris Murphy ${ }^{\star}$, Hanumant Singh ${ }^{\star}$, Claire Pontbriand ${ }^{\dagger}$, Robert A. Sohn ${ }^{\dagger}$, Sandipa Singh ${ }^{\star}$, Taichi Sato ${ }^{\ddagger}$, Chris Roman`, Ko-ichi Nakamura ${ }^{\natural}$, Michael Jakuba ${ }^{\sharp}$, Ryan Eustice $^{\infty}$, Richard Camilli ${ }^{\star}$, John Bailey ${ }^{\star}$

${ }^{\star}$ Dept. of Applied Ocean Physics and Engineering

Woods Hole Oceanographic Institution

Woods Hole, MA 02543 USA

\{ckunz, cmurphy, hsingh, ssingh, rcamilli, jbailey\}@whoi.edu

${ }^{\dagger}$ Dept. of Geology and Geophysics Woods Hole Oceanographic Institution Woods Hole, MA 02543 USA \{ccwillis, rsohn\}@whoi .edu $\ddagger$ Ocean Research Institute University of Tokyo Nakano, Tokyo 164-8639, JAPAN taichix@ori.u-tokyo.ac.jp

${ }^{\diamond}$ Dept. of Oceanography

University of Rhode Island

Narragansett, RI 02882 USA

cnr@gso .uri.edu

${ }^{\natural}$ National Institute of Advanced Industrial Science and Technology

Tsukuba, Ibaraki 305-8567, JAPAN

koichi.nakamura@aist.go.jp

\#Australian Centre for Field Robotics

University of Sydney

Sydney NSW 2006 AUSTRALIA

jakuba.jhu@gmail.com

${ }^{\infty}$ Dept. of Naval Architecture and Marine Engineering

University of Michigan

Ann Arbor, MI 48109 USA

eustice@umich.edu 

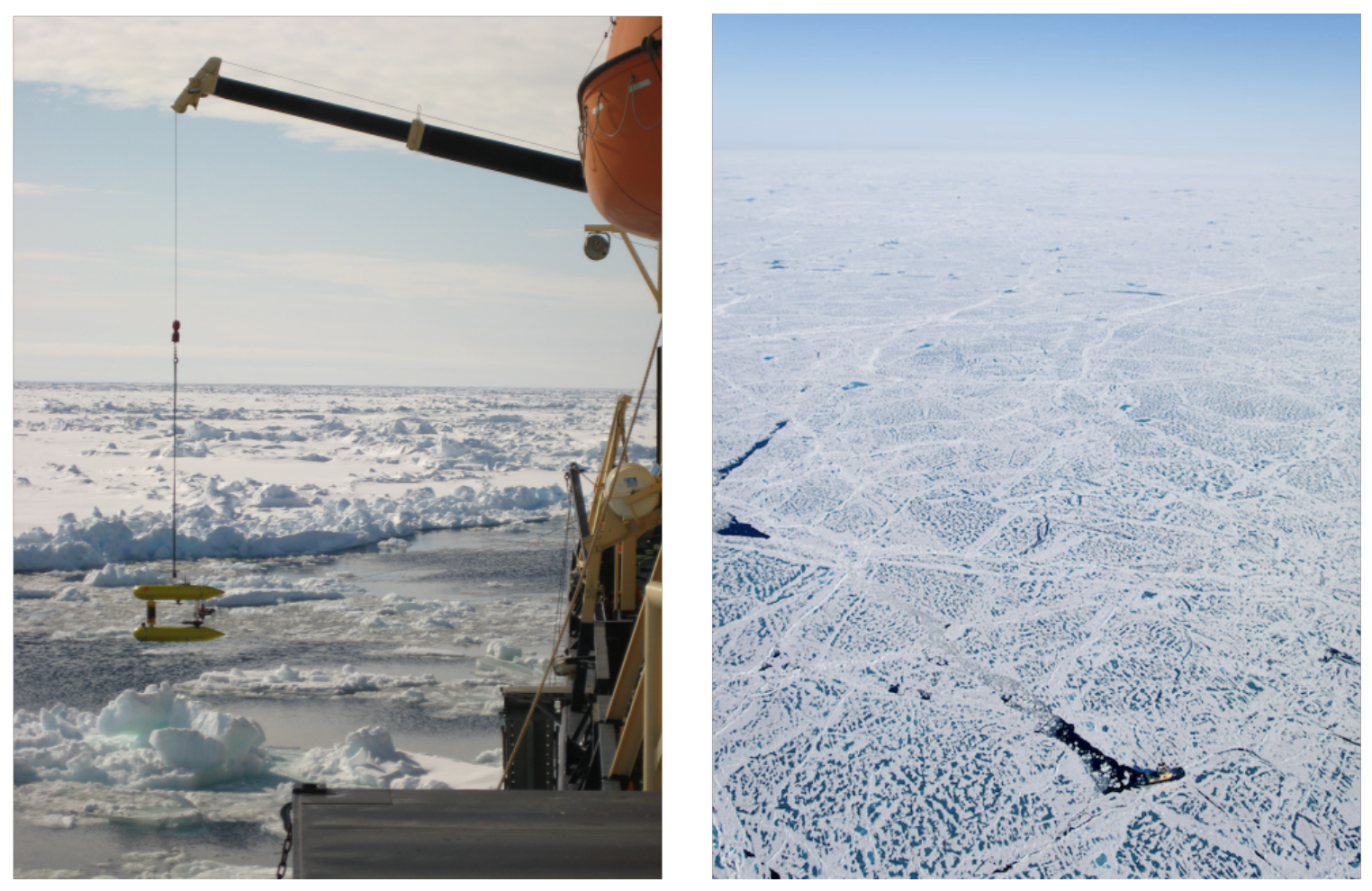

Figure 1: A typical deployment scenario for the AUV consisted of an open lead or pond into which the vehicle was released. The leads often contained large broken pieces of ice. The aerial view on the right shows a common case, in which the icebreaker (lower-right corner) copes with $90 \%$ or greater ice cover. The ship's trail of broken ice leads upward and to the left. The small dark shapes on the ice are surface melt ponds, not openings in the ice.

\begin{abstract}
This paper describes the design and use of two new autonomous underwater vehicles, Jaguar and Puma, which were deployed in the summer of 2007 at sites at $85^{\circ} \mathrm{N}$ latitude in the ice-covered Arctic Ocean to search for hydrothermal vents. These robots are the first to be deployed and recovered through ice to the deep ocean $(>3500 \mathrm{~m})$ for scientific research. We examine the mechanical design, software architecture, navigation considerations, sensor suite and issues with deployment and recovery in the ice based on the missions they carried out.

Successful recoveries of vehicles deployed under the ice requires two-way acoustic communication, flexible navigation strategies, redundant localization hardware, and software that can cope with several different kinds of failure. The ability to direct an AUV via the low bandwidth and intermittently functional acoustic channel, is of particular importance.

Based on our experiences, we also discuss the applicability of the technology and operational approaches of this expedition to the exploration of Jupiter's ice-covered moon Europa.
\end{abstract}




\section{Introduction}

Biologists have long speculated that life on Earth began in the oceans. Since the discovery of hydrothermal vents and their communities of extremophiles in 1977 (Corliss et al., 1979), astrobiologists have been excited about the prospect of searching for life in the cold oceans of other planetary bodies, most notably Jupiter's moon Europa. While work in Earth's Arctic is significantly simpler than exploring an ocean permanently covered by ice on a moon at least 600 million kilometers away, some of the lessons we learned while operating robots in the Arctic are relevant to extra-planetary exploration. The Arctic Gakkel Vents (AGAVE) expedition was a 6 week Earth-analogue mission to search the floor of the Arctic Ocean for hydrothermal vents using Autonomous Underwater Vehicles (AUVs) and other technology. While the primary goal of the expedition was to characterize one of the least-explored areas on Earth, we also gained invaluable experience in the design and use of robots under-ice that will prove useful to future Europa missions.

The target of the expedition, the Gakkel Ridge, is the Arctic extension of the global midocean ridge system. Hydrothermal vents have been found on mid-ocean ridges in all of the other oceans on Earth. The Gakkel Ridge is of particular interest to geologists because of its ultra-slow spreading rates (Dick et al., 2003), which has the potential to provide insight into the nature of the Earth's mantle. It is also of great interest to biologists, because the Arctic basin has been largely isolated from global ocean circulation for thirty million years, providing an independent arena for the evolution of life on the sea floor. The scientific case for exploration of the Gakkel Ridge was made even more compelling by recent evidence for hydrothermal venting along the ridge (Edmonds et al., 2003). All of these factors make the Gakkel Ridge an excellent Earth analogue to the frozen ocean of Europa.

In addition to the scientific interest in the Gakkel Ridge, the operating scenario presented by the area posed engineering challenges that are applicable to space exploration. The harsh conditions associated with year-round ice cover preclude the use of standard oceanographic technologies for mapping, sampling and otherwise exploring this region. Despite recent Russian manned dives near the North Pole, most submersible operators consider it too risky to send Human Occupied Vehicles under the ice. Towed and remotely operated vehicles, which typically require a tender to hold station on the surface, are also limited in their utility by the nature of icebreaker operations. Icebreakers are highly constrained in their movement by dense surface ice, and cannot move freely as an ROV may require. AUVs therefore hold the best promise for freely working on the sea floor in these limiting conditions.

In this paper, we describe our approach to the scientific exploration of the permanently-icecovered Arctic ocean with AUVs, the challenges the Arctic environment poses to robotic exploration and how we addressed them, and how the current state of the art in both technology and operations could be applied to the exploration of Europa's ocean. We start in Section 2 with an examination of previous under-ice exploration. We touch briefly on the mechanical characteristics and design considerations of the Puma and Jaguar AUVs in Section 3, and describe the peculiarities of Arctic operations in Section 4. For reliable under-ice exploration to be possible, the twin requirements of robust acoustic communications and navigation are of paramount importance, and we discuss both in Section 5. In Section 6 we 
describe software, which provides most of the fault-tolerance of the AUVs. We describe operational scenarios and experimental results in Section 7. Finally, we draw on our experiences in the Arctic to describe in Section 8 the applicabilities and extensions to our techniques for missions to Europa and other extraplanetary ice-covered oceans, before concluding in Section 9.

\section{Background}

AUVs have been used for under-ice exploration in previous expeditions to both the Arctic and the Antarctic polar regions. The Theseus AUV was used to lay optical fibre under the ice in the mid-nineties (Thorleifson et al., 1997); the Odyssey group (Bellingham et al., 1993) (McEwen et al., 2005) also conducted expeditions in the Arctic for physical oceanography applications close to the surface; the British AUTOSUB AUV gathered mid-water column scientific data with forays under the ice in the Antarctic (Griffiths and Collins, 2006); and various groups have worked in lakes (Forrest et al., 2007) and cenotes (Fairfield et al., 2007a) as analogues to Arctic and Antarctic exploration. Previous groups have also examined the particularities of operating a vehicle through a hole in the ice (Bono et al., 1998). The defining differences between these programs and ours include: a requirement for working near the sea floor in deep $(\sim 4000 \mathrm{~m})$ water; a requirement to deploy in an area that is permanently covered with ice that is drifting at about 0.2 knots for mission durations that do not allow us to maintain an open hole throughout a single dive; and the ability to accommodate a suite of scientific sensors based on the mission at hand. Given the high risk of vehicle loss, we also had a requirement to use "expendable" AUVs. Puma and Jaguar cost about $\$ 450 \mathrm{~K}$ each, while commercial AUVs designed to work at the same depths cost on the order of $\$ 2 \mathrm{M}$ to $\$ 3 \mathrm{M}$.

AUVs such as ABE have been used to search for hydrothermal vents in open oceans (Jakuba et al., 2005); we attempted to follow the same general search strategy employed in these previous expeditions, which is to start with a wide-area CTD survey to find a non-buoyant plume, and then use AUVs to survey successively smaller areas until a vent is located. The combination of weak stratification of the Arctic Ocean and the limited ability to perform a thorough CTD survey rendered this strategy less effective, unfortunately. Perhaps the most relevant related work from an extra-planetary exploration perspective is that of the AUTOSUB team, which has deployed AUVs from open water to areas under thick ice shelves in the Antarctic. The problems we faced complement those faced by AUTOSUB: while we were operating under comparably thin ice (about $3 \mathrm{~m}$ on average), we had no choice but to deploy and recover Puma and Jaguar though the ice.

\section{Mechanical Design}

The two AUVs, Puma and Jaguar, designed specifically for this mission are identical in their system design, differing only in their sensor payload. They are based on the proven Seabed (Singh et al., 2004) AUV. Our design constraints included a requirement for inexpensive vehicles with the ability to accommodate a wide suite of sensors. Puma is shown in Figure 


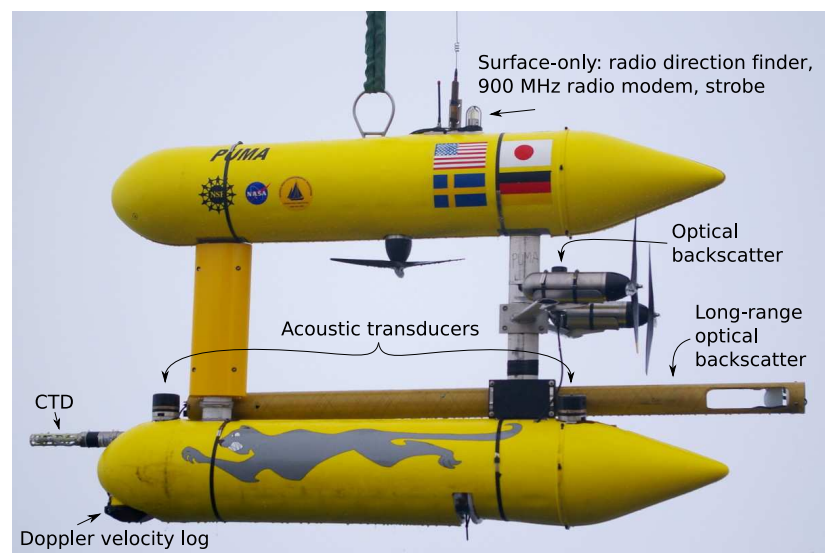

Figure 2: Puma hangs from the shipboard crane after recovery, with several sensors indicated. Not visible are the fiber-optic gyro, the depth sensor, and the Eh sensor, all of which are inside the fairing.

\section{2.}

The vehicles consist of two hulls connected by a pair of aluminum spars. Each hull contains a single large pressure housing, and syntactic foam for ballast. Most of the negative buoyancy is in the lower hull, while most of the positive bouyancy is in the upper hull; this gives the vehicle a large meta-centric height making it naturally stable in roll and pitch. The vehicles are designed for low-speed photographic and acoustic bathymetric mapping, and are designed to "fly" within a few meters of a rugged undulating sea floor. This double hull configuration is in contrast to the single-hulled torpedo-shaped vehicles that comprise the shape of choice for certain oceanographic higher speed surveys of physical and chemical water characteristics, where working close to the sea floor is not as important. We selected foam and pressure housings rated to a maximum depth of 6000 meters; in practice our operating depth was slightly more than 4000 meters. The lower pressure housing contains the batteries and the fiber optic gyro, while the upper pressure housing contains the computer which controls the vehicle. Other sensors are either contained in their own pressure housings, or are in sealed glass spheres when an opaque housing could not be used (for example in the case of the camera's strobe). Fully assembled, the vehicles are about 2 meters long, 1.5 meters tall, and weigh about 250 kilograms in air. Near-neutral buoyancy is essential for efficient vehicle control, and can be difficult to achieve.

The vehicles are driven using three thrusters with propellors mounted to the shafts. Two thrusters are mounted between the two hulls at the aft of the vehicles, and are used in a differential-drive configuration, providing both foward thrust and heading control. The third thruster, mounted to the top hull, provides vertical thrust. The propellors turn at a maximum of 150 RPM and consume about 100 watts of power each at that speed, providing a working forward velocity of about 35 centimeters per second, and a vertical velocity of 20 centimeters per second (12 meters per minute). The individual hull shapes were chosen to minimize drag. Subsequent to the hull design, however, we made a systems-level decision to ballast and run the vehicles with a downward pitch of about fifteen degrees. This allows the main thrusters to assist the vertical thruster somewhat in maintaining depth. 
The vehicles carry 64 lithium ion batteries, providing $6 \mathrm{kWh}$ of capacity, and allowing at least 24 hours of operations depending upon the hotel load of the sensors. The deep ocean is at nearly freezing temperatures throughout the world, so no additional concern for battery life while operating in the Arctic was necessary. Recharging the batteries was a problem, however, as the air temperature on the surface also hovered around freezing throughout the expedition.

During the AGAVE expedition, Puma and Jaguar operated without descent weights, and spent as much as half of their power budget during each dive during the descent and ascent phases. We operated this way to reduce complexity and increase safety.

Under-ice operations required additional backup equipment not typically used in open ocean AUV deployments. The two vehicles carried a completely separate acoustic beacon to which we could compute ranges even in the event that the main vehicle power was lost. They also carried an isolated radio-frequency beacon that could be used to locate vehicles trapped under the ice - these beacons were expressly designed for search and rescue of human avalanche victims, but they also work well for finding robots with depleted batteries.

\subsection{Sensor Suite}

While Puma and Jaguar are outfitted with identical thrusters and navigation sensors, they differ in their science payloads and in how they are used. Both vehicles carry standard oceanographic sensors for measuring water temperature, conductivity, pressure, and salinity, as well as navigation sensors, including a 3-axis north seeking fiber optic gyro, doppler velocity log, and depth sensor. Both vehicles also carry a WHOI MicroModem for acoustic communication and navigation, described below. In addition, the AUVs carry specialized sensors used for finding hydrothermal plumes, including an "Eh" sensor for measuring oxidationreduction potential in the water (Nakamura et al., 2007). Puma (the "plume mapper") carries sensors designed for water-column surveys, most notably a pair of optical backscatter sensors for measuring the amount of particulate matter suspended in the water. Jaguar carries sensors suited to sea floor surveys, including a downward-facing optical camera and strobe, an imaging sonar, and a magnetometer. The camera takes one picture every three seconds while Jaguar is near the sea floor; this rate is fixed by the amount of time it takes for the strobe to recharge. We are currently examining the use of arrays of LEDs for underwater lighting (Howland et al., 2006), which will allow for higher frame rates at the cost of higher power consumption.

Proximity to the poles posed a unique challenge for obtaining a stable heading reference. While the magnetic pole on Earth resides in the Western Arctic, and we were working in the Eastern Arctic at $7^{\circ} \mathrm{E}$ and $85^{\circ} \mathrm{E}$ longitude and $85^{\circ} \mathrm{N}$ latitude, we were still concerned by the high dip angles at these latitudes. Given this concern we opted to integrate a true north seeking fiber-optic gyro (FOG) (IXSEA, 2008) onto our AUVs even though this was at considerable cost to the project, in terms of expense $(\sim \$ 100 \mathrm{~K})$, physical size (about a $12 \times 12 \times 12 \mathrm{~cm}$ cube) and power $(25 \mathrm{~W})$. These costs were well-justified by the flawless operation of the FOG. 


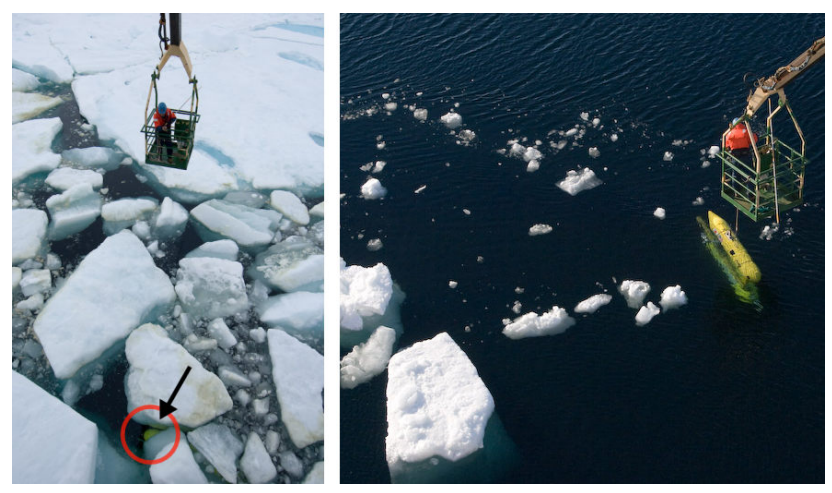

Figure 3: The size of open leads and density of the ice during AUV recovery varied greatly from dive to dive. Opening a pond sometimes also required moving the ship, temporarily precluding AUV communications. The AUV is barely visible in the left image.

\section{Under-Ice Arctic Operations}

During typical open-water AUV operations the control ship is positioned near the survey site, and an AUV is lowered from the deck and released on its mission. Once the mission is finished, or if a problem occurs, the AUV returns to the surface wherever it happens to be. If possible, the AUV is tracked while it is in the water (and in particular while it is on its way back to the surface). Once it reaches the surface, the vehicle is located visually, with the aid of a radio direction finder (RDF) or another radio-based localization scheme such as GPS coupled with an RF modem. The ship can then be driven to the AUV, to recover it.

Such a scenario is ruled out immediately for Arctic operations by the difficulty of finding and recovering an AUV through several meters of ice, and by the restrictions imposed by the ice on ship maneuverability. Underwater tracking becomes essential, rather than just convenient. Moreover it is necessary to be able to actively control the vehicle from the surface to direct it to open leads in the ice. These two requirements lead to significant changes in how the robots are built and used, and in what we as engineers did during the long periods of time that the robots were in the water.

Our basic mode of operation called for us to drive an ice-breaker to an open lead or pond within a kilometer of our area of interest. The availability of leads varied widely from dive to dive as shown in Figure 3, and conditions could change drastically from launch to recovery during a single mission. An AUV would be launched through the lead, from which it would follow a pre-programmed mission navigating primarily using acoustic beacons previously moored to the sea floor and surveyed from the ship's helicopter. Because the Arctic ice is always moving, and missions could last as long as 24 hours, the open lead used to deploy the AUV would drift kilometers away and/or close completely, rendering it unusable for recovery. We thus needed the ability to direct the AUV to a new recovery site, even in case of hardware or software failure. Each recovery featured a unique and unpredictable set of ice conditions, including acoustic shadowing and multipath from ice floes, and salinity changes caused by surface ice melt. These conditions near the surface precluded standard navigation and communications and posed the risk of a complete loss of a trapped vehicle. 
It was therefore imperative to retain as much control of the AUV as possible, despite any malfunctions.

\section{$5 \quad$ Navigation and Acoustic Communications}

Electromagnetic (EM) radiation is quickly absorbed by sea water. A typical radio modem operating in the $900 \mathrm{MHz}$ band has an effective range of only a few centimeters through seawater. Acoustic communication is the only known wireless communication method that works reliably over long distances through water. While typical surface- or air-based robots might use EM signals for both navigation (i.e. GPS) and communication (i.e. radio modems or $\mathrm{WiFi}$ ), underwater vehicles generally rely on acoustic signalling for both navigation and communication. Puma and Jaguar both use a WHOI MicroModem (Singh et al., 2006) for long-baseline (LBL (Milne, 1983)) network interrogation and for point-to-point communication between the AUVs and the ship.

\subsection{Navigation}

Since GPS does not work underwater, when underwater geo-referenced navigation is necessary a team typically deploys a set of acoustic beacons, forming an LBL network. These beacons are programmed to listen for a short sound pulse at a specific freqency (a "ping"), and respond with a pulse at a different frequency. An AUV interrogates the network by generating a query ping, and measuring how much time elapses before it hears the responses from the beacons. These travel times, together with the known locations of the deployed beacons, provide constraints on the possible locations of the robot. For a vehicle with an on-board depth sensor, two LBL beacons provide enough constraints to limit the AUV position to one of two points. If the AUV knows which side of the "baseline" it is on, the line between the two LBL beacons, then it has a fully-constrained position fix. At the second of the two AGAVE operating sites, for example, we deployed four Benthos LBL beacons from tethers suspended about 150 meters above the sea floor. Each beacon was programmed to listen for a $9 \mathrm{KHz}$ ping, and reply at a unique frequency (one each at 9.5, 10, 10.5 and 11 $\mathrm{KHz}$ ). The operating range of each beacon was about seven kilometers, so four beacons in the water gave us the flexibility to survey a fairly large area, as shown in Figure 4.

An LBL network such as this is generally sufficient for open-water operation, but in the presence of ice many otherwise easy problems became difficult (Jakuba et al., 2008). The seemingly simple tasks of deploying and surveying the locations of the LBL beacons is complicated by the limited maneuverability of the ship. We were able to work around these problems by using the ship's helicopter for the beacon survey, and in at least one case, by moving LBL beacons onto the ice for direct deployment into the water rather than from the deck of the ship.

A more tenacious problem is caused by the fact that sound does not move at a constant speed through sea water, leading to errors in pose estimates that, while small at depth, can grow to tens of meters on the surface. In open water this is usually not an important issue, but in ice, errors of this magnitude can render vehicle recovery extremely difficult. In order 
to compensate for this we deployed LBL beacons from tethers hanging over the side of the ship during recoveries, and computed independent AUV position estimates on the ship using travel times telemetered from the vehicle. To add redundancy to our pose estimates, we also made use of direct ranging measurements using a backup beacon onboard the AUV, and by using the MicroModem's built-in ranging mode. Finally, in some situations we determined AUV locations from the ship by passively listening to the robot's LBL interrogations and the network's replies, which provide hyperbolic constraints that can be combined to produce a fix.

\subsection{Communication}

The underwater acoustic channel is itself a complex, time-varying environment, being subject to severe phase distortion, Doppler spreading and multipath. The WHOI Micro-Modem is specifically designed to work in this challenging regime, providing a reliable low-power acoustic communication and navigation platform for AUVs. Frequency-shift keying modulation, along with a frequency-hop protocol, provides a relatively robust communication protocol over ranges of a few kilometers, while the navigation system is compatible with standard narrow-band LBL transponders. In addition, the modem is capable of high-rate, bandwidth-efficient uplinks with the assistance of a secondary processing card.

The challenges to acoustic commmunications are heightened by long distances (Stojanovic, 2007), and affected by environmental conditions such as sea floor makeup and water depth. AUV and surface vehicle noise transmit directly into the channel, further exacerbating the problem. Encoding information in a modulated acoustic wave brings a fundamental tradeoff between range and bandwidth. While underwater acoustic communication has achieved rates up to hundreds of kilobits per second (Stojanovic, 1996), the need for reliable acoustic communications over long distances (several kilometers) limits bandwidth to tens or hundreds of bits per second. Puma and Jaguar needed to operate on the order of seven to ten kilometers from the ship, so our communications used frequency-shift keying in the regime of 8 to $12 \mathrm{KHz}$, providing a maximum bandwidth of approximately 80 bits per second in 32-byte packets or in 13-bit "mini-packets". This allowed the AUVs maximum flexibility to explore while still preserving communications abilities.

In addition to the extreme bandwidth limitations, the acoustic channel is a shared (broadcast) medium, which implies that the possibility for acoustic collisions must be considered, particularly when the baud rate is so slow. The acoustic channel is also used for LBL navigation, as mentioned above, which further restricts the amount of communication traffic that can take place. For simplicity, we used time-division multiplexing (TDMA) to prevent collisions, and adapted our operations as necessary to cope with the relative scarcity of data available from the AUVs. On a typical deployment, we used a 90-second TDMA cycle, where each cycle contains a single 32-byte packet sent in each direction, as well as three LBL network interrogations. This resulted in an effective uplink (robot to ship) bandwidth of less than 3 bits per second.

The AUV uplink packet contained the standard vehicle state information used for monitoring open-water deployments, including pose estimate and mission goal information. In addition, 
the vehicle included the most-recent LBL travel times as quantized fixed-point values. This allowed us to employ a variety of more flexible recovery strategies that would not have been required or available on a traditional open-water deployment. In particular, a pair of LBL beacons hung from the bow and stern of the icebreaker provided a local "LBL" network with a ship-relative coordinate frame. A brief description of a standard recovery is in Section 7.3; a more detailed survey of the acoustic navigation techniques used on the trip is presented in (Jakuba et al., 2008).

Downlink (ship to robot) packets were available to abort missions, and used for directing the AUV to the ship during vehicle recovery. During recovery, the robot was sent a sequence of commands containing goal positions and depths for the robot to achieve. The positions were sent as absolute locations in the AUV's reference frame. While this required fast and careful computation on the part of operators who were primarily using the ship-relative LBL network for AUV tracking, it allowed the AUV to operate with no knowledge of ship position and orientation. This quasi-teleoperation or "acoustic tether" mode was far from real-time remote control, as the turnaround time between sent commands and received telemetry was always at least 90 seconds.

We found the Arctic environment to be very quiet, and were able to get reliable distance estimations from LBL beacons on the order of seven kilometers from the AUV. Our acoustic communications were reliable at depths shallower than about 3000 meters; we were only occasionally able to send or receive a full 32-byte packet deeper than this. While use of directional transponders such as those employed by the Hugin AUV for "acoustic tethering" (Kristensen and Vestgard, 1998) could have increased this range, the limitations on ship mobility in the presence of ice required us to use an omnidirectional transponder. Near the sea floor even 13-bit minipackets sent from the AUV did not reliably arrive decodable at the ship, probably because the signal was confounded by echoes off the hard sea floor.

\section{Vehicle Software}

The onboard software is divided into two distinct processes, which run on a PC/104 computer under Linux. One of these, the control process, communicates directly with the vehicle hardware by sending control commands to the thrusters, computing pose estimates from the navigation sensors, and logging data from the science sensors. The other process controls mission execution, interpreting telemetry provided by the control process and following a user-supplied script to carry out the survey. In order to maximize the robustness of the software, we implemented several failsafes to prevent loss of vehicle control. In particular, we implemented a "safe mode," in which the robot will cancel all of its navigation goals, start to float slowly toward the surface under its own positive buoyancy, and listen for commands sent acoustically from the ship. This mode is engaged whenever:

- The on-board computer reboots (e.g. because of a power fault).

- The control process exits (e.g. because of a memory fault) - this causes a reboot triggered by an expiring watchdog timer. We coined the term "rebort" (for rebootabort) to describe this situation. 


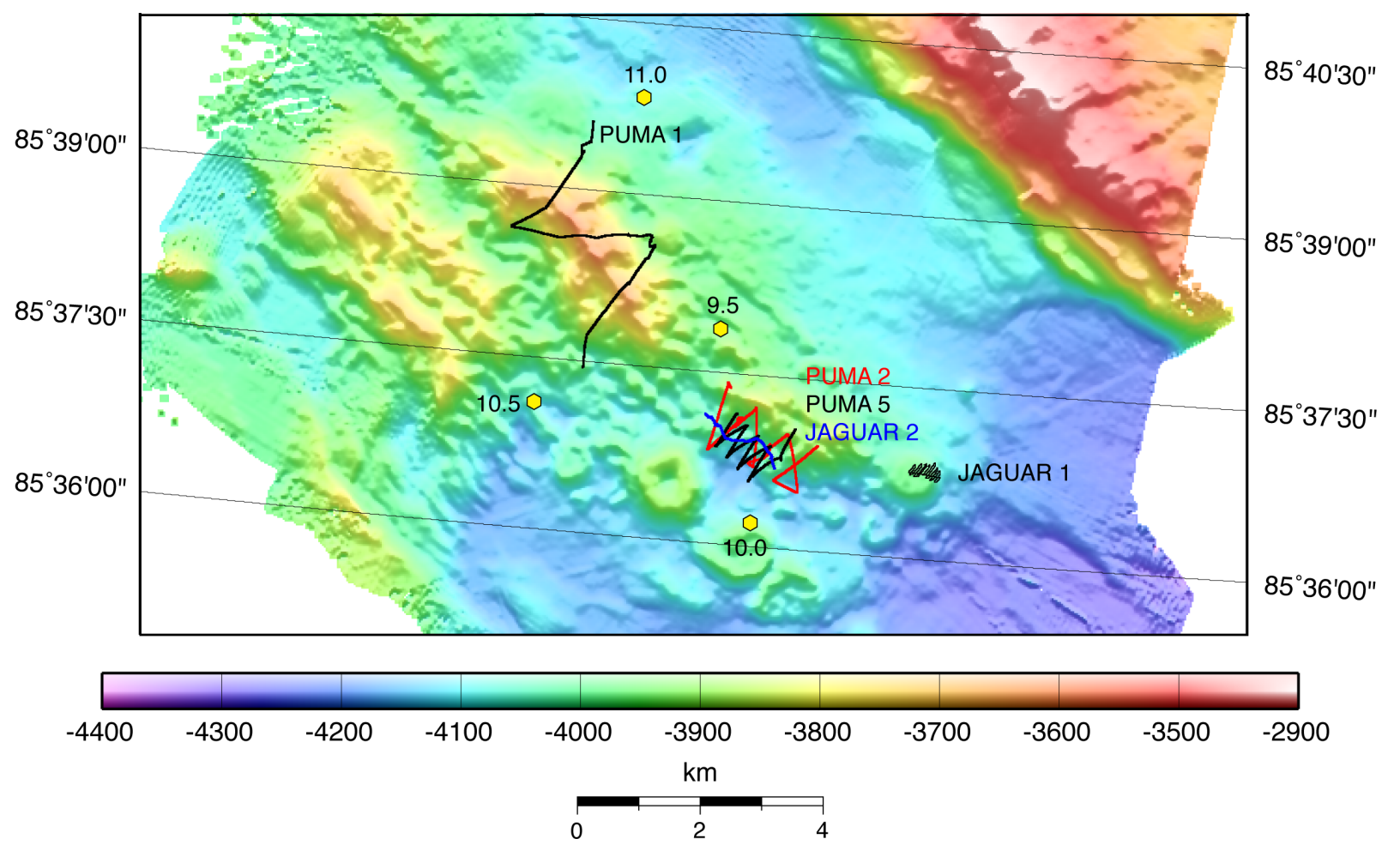

Figure 4: Actual tracklines flown during AUV missions superimposed on local bathymetry. This figure does not include the single Puma dive performed at a seperate divesite at $85^{\circ} \mathrm{N}$, $7^{\circ} \mathrm{E}$.

- An abort is sent acoustically from the ship.

- An internal mission abort is triggered (e.g. by a maximum depth being exceeded, or by a critical sensor failing).

The safe mode ensures that the robot remains in a controllable state as much as possible. Once engineers have assessed the situation, they can send position and depth goals to the AUV to control the ascent. The only situation in which a robot floats to the surface completely passively is when the on-board batteries have been depleted.

If a mission completes normally, the robot ascends under power to a pre-determined depth (usually 200 meters), after which it holds position to listen for new goal directions sent acoustically. Because the robot passively rises as slowly as 6 meters per minute, and actively at around 12 meters per minute, there is adequate time in coming up from 4000 meters to find a lead for recovery, move the ship, and re-establish acoustic communications with the AUV to "drive it home." 


\section{$7 \quad$ Performance and Results}

\subsection{Overall Results}

During the summer of 2007, we made two trips to the Arctic. The first trip was a 14-day engineering trial to ice just north of Svalbard, and the second was the 6-week expedition to two sites along the Gakkel Ridge, at $85^{\circ}$ north latitude. During the course of the expedition, we deployed Puma six times, and deployed Jaguar three times, in addition to numerous short test dives with both vehicles to depths less than 200 meters. Five of the mission tracks followed by the AUVs at the $85^{\circ} \mathrm{N}, 85^{\circ} \mathrm{E}$ site are shown in Figure 4 . In addition to the AUVs, the science team made use of a towed sled with sampling capabilities called CAMPER, a traditional oceanographic CTD carousel, and a network of seismographs deployed directly onto the ice. The crew of the ship, the Swedish icebreaker Oden, also made use of ice drift buoys to estimate the motion of the ice pack.

The details of our scientific results have been described in (Sohn et al., 2007) and (Shank et al., 2007). In the early days of the expedition, the science party devoted most of its time to ship-based multibeam surveys and CTD casts, both of which were restricted by the ice. Once an area of interest was established and LBL beacons were deployed, we began making AUV dives, continuing CTD casts when possible. Toward the end of the expedition, more time was spent using CAMPER, which provided bottom sampling capabilities and live High-Definition video from the sea floor, at the cost of reduced mobility compared to an AUV. CAMPER was towed just above the seafloor directly beneath the ship, which passively drifted with the ice during deployments. Of all the resources deployed during the expedition, only the AUVs had the capability to maneuver independently of the ship. While we did not find any hydrothermal vents, the AUVs mapped chemical markers of hydrothermal activity and produced microbathymetric maps, and the CTD and CAMPER produced images and samples of several previously unknown microbial species, and evidence of explosive volcanism at unprecedented ocean depths (Sohn et al., 2008).

\subsection{AUV Performance}

Puma and Jaguar made nine deep dives during the course of the expedition. Of these, five produced useful scientific data, while all nine were useful from an engineering perspective. The dives are summarized in Table 1. The three Puma dives with zero bottom time experienced software failures during the descent, leading to "rebort" conditions, which were later resolved. The JAGUAR2 dive was aborted acoustically from the Oden, after we determined from telemetry that the vehicle was malfunctioning. The JAGUAR3 dive ended with a passive ascent, after Jaguar depleted its batteries. In all dives except JAGUAR1 and JAGUAR3, engineers were able to communicate acoustically with the vehicles during recovery, and in every case we were able to make range measurements to the AUVs using either the primary modem, or the backup beacon.

The Puma dives produced data similar to that shown in Figure 7. Once the vehicles were back on the deck of the Oden, most engineering and sensor data were available to scientists within 
Table 1: Summary of the nine dives past 100 meters made by AUVs during the AGAVE expedition.

\begin{tabular}{c|l|l|l|l|l|l}
\hline Dive ID & Start Time & $\begin{array}{l}\text { Max. } \\
\text { Depth }\end{array}$ & $\begin{array}{l}\text { Descent } \\
\text { Time }\end{array}$ & $\begin{array}{l}\text { Bottom } \\
\text { Time }\end{array}$ & $\begin{array}{l}\text { Ascent } \\
\text { Time }\end{array}$ & $\begin{array}{l}\text { Recovery } \\
\text { Time }\end{array}$ \\
\hline \hline Puma 1 & $10 / 07 / 200704 \mathrm{~h} 12$ & $1025 \mathrm{~m}$ & $1 \mathrm{~h} 42 \mathrm{~m}$ & $0 \mathrm{~h} 00 \mathrm{~m}$ & $1 \mathrm{~h} 24 \mathrm{~m}$ & $3 \mathrm{~h} 08 \mathrm{~m}$ \\
Puma 2 & $16 / 07 / 200713 \mathrm{~h} 26$ & $3417 \mathrm{~m}$ & $5 \mathrm{~h} 32 \mathrm{~m}$ & $6 \mathrm{~h} 43 \mathrm{~m}$ & $4 \mathrm{~h} 09 \mathrm{~m}$ & $3 \mathrm{~h} 48 \mathrm{~m}$ \\
Puma 3 & $19 / 07 / 200722 \mathrm{~h} 26$ & $3512 \mathrm{~m}$ & $4 \mathrm{~h} 51 \mathrm{~m}$ & $7 \mathrm{~h} 10 \mathrm{~m}$ & $8 \mathrm{~h} 01 \mathrm{~m}$ & $1 \mathrm{~h} 21 \mathrm{~m}$ \\
Jaguar 1 & $21 / 07 / 200720 \mathrm{~h} 55$ & $2234 \mathrm{~m}$ & $3 \mathrm{~h} 58 \mathrm{~m}$ & $0 \mathrm{~h} 00 \mathrm{~m}$ & $8 \mathrm{~h} 00 \mathrm{~m}$ & $\sim 6 \mathrm{~h}$ \\
Puma 4 & $22 / 07 / 200721 \mathrm{~h} 58$ & $192 \mathrm{~m}$ & $0 \mathrm{~h} 23 \mathrm{~m}$ & $0 \mathrm{~h} 00 \mathrm{~m}$ & $0 \mathrm{~h} 17 \mathrm{~m}$ & $1 \mathrm{~h} 30 \mathrm{~m}$ \\
Puma 5 & $23 / 07 / 200718 \mathrm{~h} 39$ & $293 \mathrm{~m}$ & $0 \mathrm{~h} 28 \mathrm{~m}$ & $0 \mathrm{~h} 00 \mathrm{~m}$ & $0 \mathrm{~h} 31 \mathrm{~m}$ & $1 \mathrm{~h} 34 \mathrm{~m}$ \\
Puma 6 & $25 / 07 / 200712 \mathrm{~h} 17$ & $3560 \mathrm{~m}$ & $5 \mathrm{~h} 28 \mathrm{~m}$ & $5 \mathrm{~h} 40 \mathrm{~m}$ & $5 \mathrm{~h} 07 \mathrm{~m}$ & $0 \mathrm{~h} 38 \mathrm{~m}$ \\
Jaguar 2 & $27 / 07 / 200701 \mathrm{~h} 02$ & $3995 \mathrm{~m}$ & $7 \mathrm{~h} 54 \mathrm{~m}$ & $5 \mathrm{~h} 20 \mathrm{~m}$ & $5 \mathrm{~h} 44 \mathrm{~m}$ & $2 \mathrm{~h} 00 \mathrm{~m}$ \\
Jaguar 3 & $29 / 07 / 200701 \mathrm{~h} 05$ & $4062 \mathrm{~m}$ & $7 \mathrm{~h} 18 \mathrm{~m}$ & $19 \mathrm{~h} 31 \mathrm{~m}$ & $<5 \mathrm{~h}$ & $\sim 2 \mathrm{~h} 30 \mathrm{~m}$
\end{tabular}

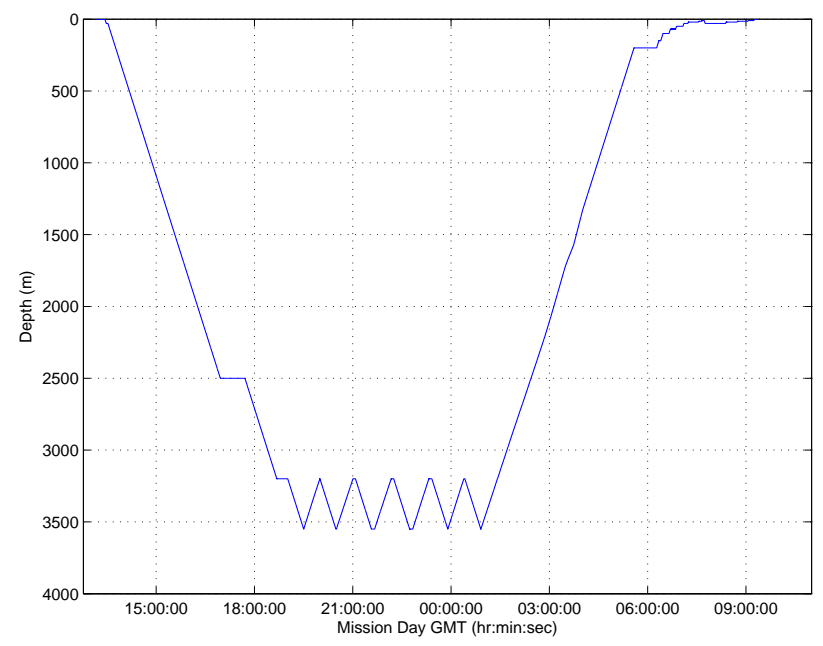

Figure 5: AUV depth versus time for AGAVE PUMA2 mission. Note the up and down "Towyo" motion once the AUV reaches the operating depth.

a matter of minutes, to allow for immediate planning of the next steps in the expedition.

\subsection{A Typical Dive}

The second Puma dive, PUMA2, was primarily for hydrothermal plume detection and localization, using the Eh, CTD, and optical backscatter sensors. The mission called for the Puma AUV to perform 3 transects of a $1.9 \mathrm{~km}$ by $1.9 \mathrm{~km}$ area while "towyo"-ing; oscillating in depth between $3200 \mathrm{~m}$ and $3550 \mathrm{~m}$ through the estimated depth of a non-buoyant hydrothermal plume. Figure 5 shows the depth of the AUV against mission time.

AUV deployment was performed as shown in Figure 1. The AUV was attached to the shipboard crane, and lowered into the water. Pre-dive hardware and software readiness checks were performed, including adjusting the ballast to compensate for changes in the 


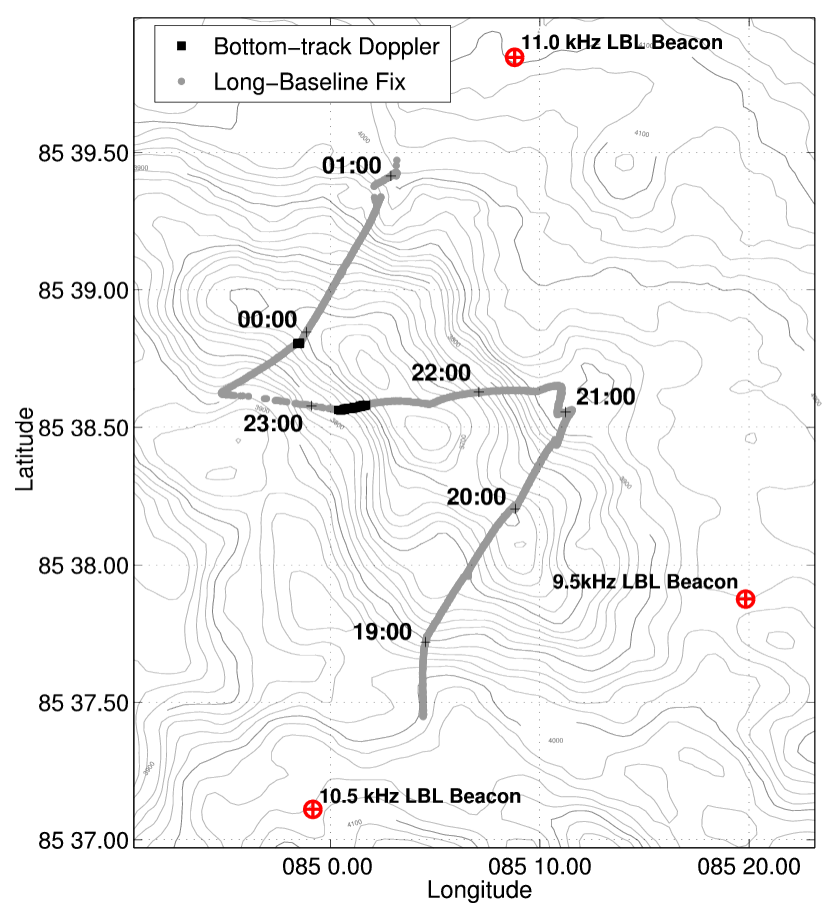

Figure 6: The tracklines run by the AUV during the AGAVE PUMA2 mission. The The gray dots show fixes from the Long-Baseline navigation net, and the larger black dots show where bottom track fixes were available from the vehicle's Doppler Velocity Log. LBL travel times used for navigation were mostly consistent, though the AUV lost contact with one beacon and overshot one corner of the path (at left) before returning to the planned tracklines.

scientific payload. We interpreted the amount of energy used by the vertical thruster during the previous dive as an indicator of the vehicle's ballast at depth. We attempted to ballast the vehicles so that they were one kilogram positive when at depth. In some cases icemelt caused a decrease in salinity on the surface and resulted in the vehicle being neutrally or very slightly negatively buoyant when near the surface of the water. After starting the mission, we would detach the crane's tether from the AUV, which would then start to dive.

At 30m depth, the AUV paused to provide an opportunity for an acoustic abort if the telemetry suggested anything was amiss early in the mission. The vehicle then continued on to $2500 \mathrm{~m}$, where it transited horizontally until it was directly above its first waypoint. While the Arctic provided an excellent environment for acoustic communications, transiting well above the sea floor ensured that LBL transponders were not shadowed by the mountainous bathymetry, and reduced the chance for interference due to multipath induced by the sea floor. After reaching the first trackline waypoint, the vehicle dove to $3200 \mathrm{~m}$ and began its "towyo" behavior.

The AUV was configured to use doppler bottom track for navigation when possible, and to use LBL navigation when bottom track was unavailable. Since this dive was run primarily in the middle of the water column, LBL navigation was primarily used as shown in Figure 6. After completing the mission, the vehicle ascended to $200 \mathrm{~m}$ and waited for further waypoints transmitted acoustically from the Oden. Engineers onboard the ship computed the 

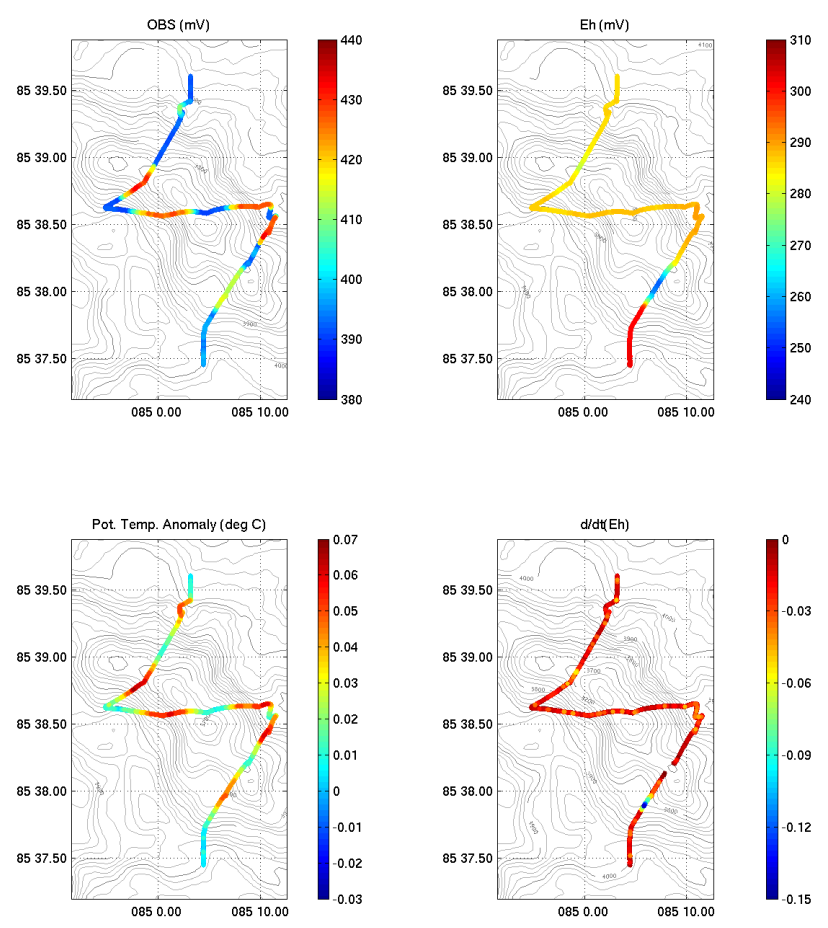

Figure 7: Chemical sensor traces overlaid on mission track. There is an Eh anomaly indicated by the bright area in the lower right subplot's trackline.

correct waypoints to use, and sent them to Puma following the robot's normal communications TDMA cycle. On this dive, Puma's chemical sensors detected a number of anomalies consistent with a non-buoyant hydrothermal plume, as shown in Figure 7.

The AUV recovery process is represented in detail in Figure 8. After completing the tracklines, the AUV rose to a depth of $200 \mathrm{~m}$. The Oden was approximately $750 \mathrm{~m}$ horizontal distance from the AUV, next to an opening in the ice pack where the AUV could surface. Ice drift greatly complicated recovery, as the AUV could not be directed to any single static location. Drift caused the ship to move away from the AUV at up to 25 centimeters per second, leading the AUV to drive for over two hours "chasing" the ship before catching up. During this time, the AUV telemetered back travel times to the two ship-mounted navigation beacons which were used by engineers on board to calculate a vehicle location fix. These fixes are displayed in Figure 8 as dots; note that the vehicle itself was not capable of computing positions as it did not know the position of the ship.

In response, AUV operators sent a sequence of acoustic commands directing depth and bearing changes for the AUV to follow. These changes are represented in the figure as arrows in the direction of the requested bearing, or octagons where the AUV was ordered to hold its horizontal position. The bearing changes were sent as absolute points for the AUV to drive to; this prevented the AUV from driving forever if communications were impeded. For clarity, commands have been omitted from Figure 8 when they were sent only to extend the destination point, allowing the AUV to continue along the same bearing. 

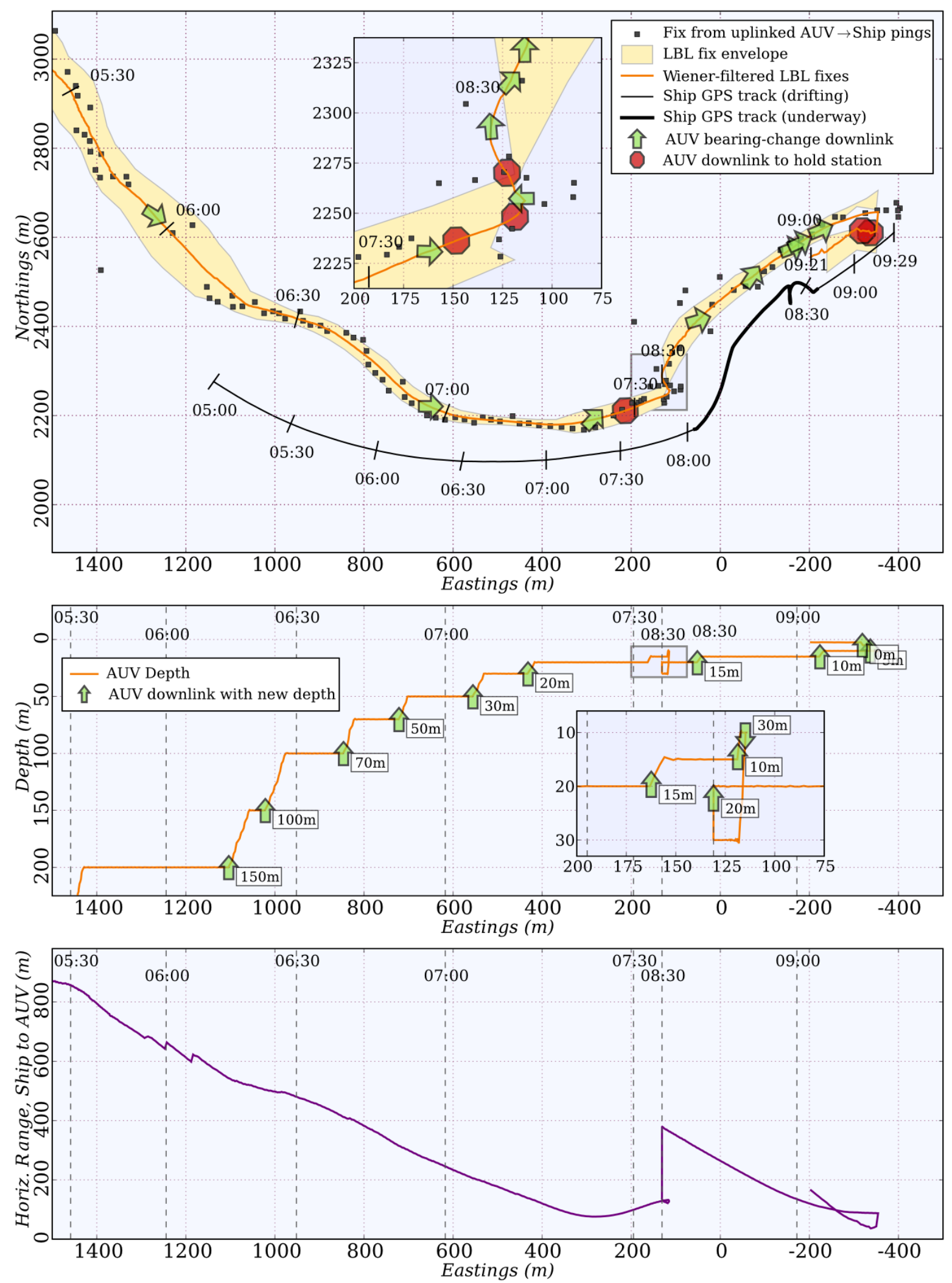

Figure 8: These plots provide three different views of the AUV recovery. The top plot shows the ship and AUV tracks, along with error bounds on the AUV position. The middle plot shows the AUV depth throughout the recovery. The bottom plot shows the horizontal range from the ship to the AUV over the course of the dive. 


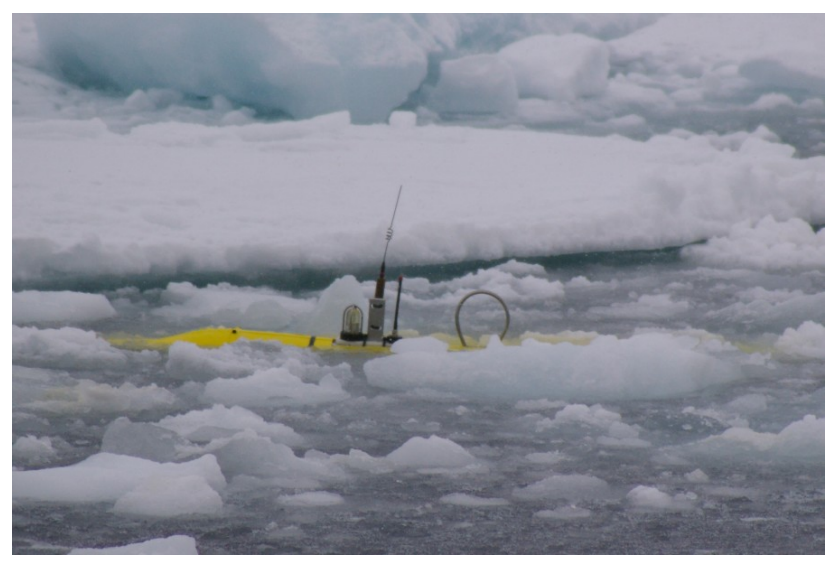

Figure 9: Puma surfaces in ice near the pond edge after PUMA2.

During this time, the AUV was gradually brought to a depth of $30 \mathrm{~m}$ as it swam progressively closer to the ship. The AUV moves faster in shallower water, which is captured and carried along with the drifting ice, but communications are less reliable at shallow depths, due to acoustic multipath caused by the sea ice. When the AUV reached the ship around 7:45, the recovery opening had become clogged with ice. To clear the recovery pond, the AUV was directed to hold depth at $30 \mathrm{~m}$ while the shipboard LBL transponders and telemetry transducer were removed from the water. After the icebreaker had cleared the hole of ice, the vehicle ascended to a few meters depth and drove straight towards the ship from about $100 \mathrm{~m}$ away. At a range of about $30 \mathrm{~m}$, the vehicle was spotted from the helicopter deck and brought to the surface.

The AUV surfaced in a section of slush ice near the edge of the pool. After dives, we recovered the AUVs using either the Oden's small boat, or a basket attached to a crane lowered over the side of the ship, depending on the amount of open water and the proximity of the AUV to the Oden. On two occasions we recovered Jaguar using the ship's helicopter as the AUV was too far away to be reached efficiently by the Oden or its small boat.

\section{Future work and extra-terrestrial applications}

The AGAVE expedition was unusual in that the combination of scientific goals and the physical environment to be explored necessitated the use of autonomous robots. The expedition thus had the twin goals of advancing the state of the art in sub-ice robotic exploration, and of characterizing the geological, chemical, and biological activity of a previously unexplored area. These goals would fall directly in line with those of an eventual mission to Europa. In this section we discuss the applicability of the lessons we learned in the Arctic to these potential future missions.

First of all, we cannot address the issues involved with actually getting an underwater vehicle into the presumed Europan ocean. Access to the Arctic, while logistically and politically difficult, is not really comparable to the engineering challenges that would need to be addressed to transport an underwater vehicle to another moon, and then to deploy it through ice many 
kilometers thick (Turtle and Pierazzo, 2001) into the ocean below. The mechanical design of such a vehicle would also be highly mission dependent, so we will not discuss that here. We can, however, address the necessity for reliable acoustic communication and navigation capabilities on such a vehicle, which we will focus on.

During the AGAVE expedition, we attempted to maintain continuous acoustic communications with AUVs in the water. Often it was the case that the icebreaker drifted out of communications range, and we sometimes passed well over an hour without hearing a signal. We could still localize the AUV in these circumstances using lower-bandwith ranging pings, but we could not be certain of vehicle health. Without more powerful transducers, the limited length of this "acoustic leash" would likely seriously impair the effectiveness of a Europa mission, because of the limited volume of water that an AUV could explore while maintaining the ability to telemeter data back to Earth (presumably via a base station left at the water-ice interface). This limitation could be overcome by a network of autonomous acoustic relay beacons, or by an AUV which periodically returns to a point within acoustic range of the surface. The former strategy would have the added benefit that the relay beacons could be used as localization landmarks, and in fact we have proposed such a strategy for use in AGAVE follow-on expeditions. We have also begun investigating ways to make mission-level decisions based on very-low bitrate acoustic telemetry of scientific data, while the AUV is still deep in the water(Murphy and Singh, 2008). These strategies could be adapted to facilitate decision-making for the extreme case of a low-bandwidth acoustic link coupled with a low-bandwidth long-range radio link through space.

We described above our use of LBL beacons fixed to the sea floor. We deployed these beacons from the icebreaker, its helicopter, or from the surface, and determined their deployed locations using the helicopter by ranging to the beacons from several GPS-localized positions. Such a fixed-asset navigation network is convenient for open-ocean operation, and not prohibitively difficult to deploy and use under ice, but is not necessary for accurate navigation. One alternative we have been exploring, described in (Eustice et al., 2007), is to transmit localization information (e.g. a GPS position) from the ship to an AUV. Using precise clock synchronization and TDMA management, ship-to-AUV ranges can be computed by the AUV without the need for a bidirectional acoustic link. The surface vessel then becomes a moving beacon, and successive messages can be combined with AUV odometry to constrain the set of possible AUV locations, ultimately producing a "running fix." For the odometry, the combination of a doppler velocity log and a heading reference may be sufficient. It is interesting to note that the methodologies adopted for heading references in extra terrestrial navigation, namely constellation or sun tracking (Deans et al., 2005) were the methodologies of choice by high latitude exploration missions in the 19th century (Liljequist, 1993). These methods would not serve for a Europa mission under the ice. Although there is evidence to suggest that Europa has an iron core, some form of gyro would be the ideal heading reference for such a mission.

Given the recent advances in the field of simultaneous localization and mapping (SLAM), it is worthwhile to consider its applicability to underwater exploration of unknown environments. Most SLAM approaches rely either on fixed identifiable landmarks, or on scan-matching minimally processed sensor measurements. Either approach would likely work near the underside of the ice, or near the sea floor, where features can be identified either with 
acoustic or optical sensors; see, for example, (Fairfield et al., 2007b) and (Eustice et al., 2008). In the mid-water column, however, such techniques would not be possible without the insertion of artificial landmarks, as described above. Given the combined utility of communication relay beacons that can also serve as navigation landmarks, it seems most prudent to combine several techniques, allowing a group of (moving) AUVs to collectively serve as a communication network and as a self-sufficient navigation infrastructure; such a networks are described and analyzed in (Bahr, 2008). The use of multiple AUVs in this way would increase redundancy as well as the potential science return.

Table 2 summarizes the applicability of the lessons we learned during AGAVE to extraplanetary exploration. As we mentioned above, the most transferrable ideas are in the domains of communication, "acoustically tethered" remote guidance, and acoustic localization. 
Table 2: Comparisons between Arctic and Europa mission elements.

\begin{tabular}{|c|c|c|c|}
\hline Mission Element & Arctic & Europa & Issues \\
\hline Navigation infrastructure & $\begin{array}{l}\text { Surveyed LBL network plus ship- } \\
\text { deployed beacons }\end{array}$ & $\begin{array}{l}\text { Ice-based beacon(s), satellite- } \\
\text { referenced. Fleet of AUVs can serve as } \\
\text { beacons and communications network }\end{array}$ & $\begin{array}{l}\text { Thick, drifting ice, difficult contact be- } \\
\text { tween surface and ice/liquid boundary }\end{array}$ \\
\hline Communications methodology & $\begin{array}{l}\text { Acoustic-only communications in the } \\
\text { water }\end{array}$ & $\begin{array}{l}\text { Acoustic water-to-ice, plus wired or } \\
\text { radio ice-to-ice, plus radio surface to } \\
\text { Earth }\end{array}$ & Unknown ice dynamics, thickness \\
\hline Mechanical design & Oceanographic-grade construction & Reduced size, foldable for transport & $\begin{array}{l}\text { Long deployment requires extremely } \\
\text { robust hardware }\end{array}$ \\
\hline On-board navigation sensors & $\begin{array}{l}\text { Depth, fiber-optic gyro, doppler veloc- } \\
\text { ity log }\end{array}$ & Largely the same & $\begin{array}{l}\text { Gyro requires planetary rotation, lati- } \\
\text { tude fix. Other heading references also } \\
\text { problematic. }\end{array}$ \\
\hline Site accessibility & Accessible by conventional icebreaker & $\begin{array}{l}\text { Surface ice must be drilled or melted } \\
\text { through }\end{array}$ & $\begin{array}{l}\text { Portable technology not yet available } \\
\text { for multi-kilometer thick ice penetra- } \\
\text { tion }\end{array}$ \\
\hline Deployment scenarios & Individual dives, up to 24 hours long & Single, long-term deployment & $\begin{array}{l}\text { Mission plans and telemetry must be } \\
\text { communicated acoustically }\end{array}$ \\
\hline Science payload & $\begin{array}{l}\text { Chemical, physical oceanographic sen- } \\
\text { sors }\end{array}$ & $\begin{array}{l}\text { The same, plus sampling capability and } \\
\text { in-situ analysis }\end{array}$ & Sampling can change buoyancy \\
\hline Power & $\begin{array}{l}6 \mathrm{kWh} \text { battery array, recharged be- } \\
\text { tween dives }\end{array}$ & $\begin{array}{l}\text { Battery array, recharged by on-board } \\
\text { radioisotope thermal generator }\end{array}$ & $\begin{array}{l}\text { RTGs can not source high current } \\
\text { loads; batteries would be necessary for } \\
\text { powering thrusters }\end{array}$ \\
\hline
\end{tabular}




\section{Conclusions}

During the summer of 2007, we demonstrated that autonomous underwater vehicles can be effectively used for scientific research under the permanent ice pack. We refined traditional AUV design and operations as necessary to reliably deploy and recover vehicles in the harsh Arctic environment. The AGAVE expedition can be thought of as a baseline for future sub-ice robotic exploration, in the Arctic, the Antarctic, and even on other planetary bodies. Among many lessons learned, the fundamental requirement for reliable acoustic communications should be taken as a starting point for future development of sub-ice vehicles.

In addition to the advancement of AUV technology, the AGAVE expedition resulted in several scientific discoveries in its own right. These discoveries further validate the use of robotic technology for the exploration of the sea floor.

Now that we have a grasp of how to effectively use AUVs under the ice pack, there are several additional capabilities that we envision. The most notable of these would be the ability to sample the deep environment, and perform in-situ analysis of samples. These abilites would also require the cognitive ability to know when and what to sample, and collected as a system, would yield a self-contained science platform for long-term autonomous deployment.

At a more mundane level, for Arctic exploration, several simple changes using proven technology should be taken, including the use of descent weights to reduce the amount of time and energy spent reaching the sea floor (ascent weights are less advisable, since a large amount of positive buoyancy would make maneuvering an AUV to an open lead quite problematic). Finally, the ability to deploy and coordinate multiple AUVs in the water simultaneously could enable cooperative missions and increase data acquisition abilities, but increase complexity significantly. Toward the end of the AGAVE expedition, we deployed the CTD carousel during AUV dives, but we never had both AUVs in the water at the same time. Since then, we have started experiments with multiple-vehicle operations, but none yet under ice. Multi-AUV operations makes a great deal of sense when dives last several hours, and even more so when an entire mission comprises just one dive.

In summary, the technology and expertise needed to explore the ice-covered oceans now exists. More development is needed to bring the technology to maturity, and to adapt it for exploration further afield, but the positive results of the AGAVE expedition show that the robots can effectively, and relatively inexpensively, be used for under-ice exploration with less risk than that posed by manned exploration.

\section{Acknowledgements}

This work was made possible in part through NSF OPP grant OPP-0425838, through the NASA ASTEP program through grant Z601701, through NSF Censsis ERC through grant EEC-9986821 and through funding from the Woods Hole Oceanographic Institution. The authors thank the AGAVE science party, the Swedish Polar Research Secretariat, and the crew of the Oden. 


\section{References}

Bahr, A. (2008). Cooperative Localization for Autonomous Underwater Vehicles. PhD thesis, Massachusetts Institute of Technology.

Bellingham, J., Chryssostomidis, C., Deffenbaugh, M., Leonard, J., and Schmidt, H. (1993). Arctic under-ice survey operations. In International Symposium on Unmanned Untethered Submersible Technology, pages 50-59, University of New Hampshire.

Bono, R., Bruzzone, G., Caccia, M., Spirandelli, E., and Veruggio, G. (1998). Romeo goes to Antarctica. In Proceedings of the IEEE/MTS Oceans Conference and Exhibition, volume 3, pages 1568-1572, Nice, France.

Corliss, J. B., Dymond, J., Gordon, L. I., Edmond, J. M., von Herzen, R. P., Ballard, R. D., Green, K., Williams, D., Bainbridge, A., Crane, K., and van Andel, T. H. (1979). Submarine thermal springs on the Galápagos rift. Science, 203(4385):1073-1083.

Deans, M. C., Wettergreen, D., and Villa, D. (2005). A sun tracker for planetary analog rovers. In 8th International Symposium on Artificial Intelligence, Robotics and Automation in Space.

Dick, H. J. B., Lin, J., and Schouten, H. (2003). An ultraslow-spreading class of ocean ridge. Nature, 426:405-412.

Edmonds, H. N., Michael, P. J., Baker, E. T., Connelly, D. P., Snow, J. E., Langmuir, C. H., Dick, H. J. B., Muhe, R., German, C. R., and Graham, D. W. (2003). Discovery of abundant hydrothermal venting on the ultraslow-spreading gakkel ridge in the arctic ocean. Nature, 421:252-256.

Eustice, R. M., Pizarro, O., and Singh, H. (2008). Visually augmented navigation for autonomous underwater vehicles. IEEE Journal of Oceanic Engineering, 33(2):103-122.

Eustice, R. M., Whitcomb, L. L., Singh, H., and Grund, M. (2007). Experimental results in synchronous-clock one-way-travel-time acoustic navigation for autonomous underwater vehicles. In Proceedings of the IEEE International Conference on Robotics and Automation, Rome, Italy.

Fairfield, N., Jonak, D., Kantor, G. A., and Wettergreen, D. (2007a). Field results of the control, navigation, and mapping systems of a hovering AUV. In International Symposium on Unmanned Untethered Submersible Technology.

Fairfield, N., Kantor, G. A., and Wettergreen, D. (2007b). Real-time slam with octree evidence grids for exploration in underwater tunnels. Journal of Field Robotics.

Forrest, A., Bohm, H., Laval, B., Reid, D., Andersen, D., Magnusson, E., and Doble, M. (2007). Small AUV deployment under ice: Pavilion lake, B.C., Canada (a case study). Geophysical Research Abstracts, 9.

Griffiths, G. and Collins, K. (2006). Masterclass in AUV technology for polar science collaborative Autosub science in extreme environments. In Proceedings of the International Masterclass. Society for Underwater Technology.

Howland, J., Farr, N., and Singh, H. (2006). Field tests of a new camera/LED strobe system. In Proceedings of the IEEE/MTS Oceans Conference and Exhibition, Boston, USA.

IXSEA (2008). http://www.ixsea.com/. 
Jakuba, M., Roman, C., Singh, H., Murphy, C., Kunz, C., Willis, C., Sato, T., and Sohn, R. (2008). Long-baseline acoustic navigation for under-ice autonomous underwater vehicle operations. Journal of Field Robotics, 25(11):861-879.

Jakuba, M., Yoerger, D., Bradley, A., German, C., Langmuir, C., and Shank, T. (2005). Multiscale, multimodal AUV surveys for hydrothermal vent localization. In International Symposium on Unmanned Untethered Submersible Technology, Durham, NH.

Kristensen, J. and Vestgard, K. (1998). Hugin-an untethered underwater vehicle for seabed surveying. In OCEANS, 1998. Proceedings of MTS/IEEE, volume 1, pages 118-123.

Liljequist, G. H. (1993). High Latitudes - A History of Swedish Polar Travels and Research 1758-1980. Swedish Polar Research Secretariat.

McEwen, R., Thomas, H., Weber, D., and Psota, F. (2005). Performance of an AUV navigation system at Arctic latitudes. IEEE Journal of Oceanic Engineering, 30(2):443-454.

Milne, P. H. (1983). Underwater Acoustic Positioning Systems. Gulf Publishing Co.

Murphy, C. and Singh, H. (2008). Human-guided autonomy for acoustically tethered underwater vehicles. In Proceedings of the IEEE/MTS Oceans Conference and Exhibition.

Nakamura, K., Edmonds, H. N., Winsor, P., Liljebladh, B., Stranne, C., Upchurch, L., Singh, H., Jakuba, M., Willis, C., Shank, T., Humphris, S. E., and Reves-Sohn, R. (2007). Arctic Gakkel Ridge hydrothermal plume study by in-situ redox and particle size measurements. AGU Fall Meeting Abstracts, pages A985+.

Shank, T. M., Bailey, J., Edmonds, H., Forte, P., Helmke, E., Humphris, S., Kemp, J., Nakamura, K., Sohn, R. A., Singh, H., and Willis, C. (2007). Biological and geological characteristics of the Gakkel ridge. In EOS, Transactions of the AGU, volume 88.

Singh, H., Can, A., Eustice, R., Lerner, S., McPhee, N., Pizarro, O., and Roman, C. (2004). Seabed AUV offers new platform for high-resolution imaging. EOS, Transactions of the AGU, 85(31):289,294-295.

Singh, S., Grund, M., Bingham, B., Eustice, R., Singh, H., and Freitag, L. (2006). Underwater acoustic navigation with the WHOI Micro Modem. In Proceedings of the IEEE/MTS Oceans Conference and Exhibition, Boston, USA.

Sohn, R., Willis, C., Humphris, S., Shank, T., Singh, H., Edmonds, H., Kunz, C., Hedman, U., Helmke, E., Jakuba, M., Liljebladh, B., Linder, J., Murphy, C., Nakamura, K., Sato, T., Schlindwein, V., Stranne, C., Tausenfreund, M., Upchurch, L., Winsor, P., Jakosson, M., and Soule, A. (2008). Explosive volcanism on the ultraslow-spreading Gakkel ridge, Arctic Ocean. Nature, 453(7199):1236-1238.

Sohn, R. A., Edmonds, H., Humphris, S., Shank, T., Singh, H., Ericsson, B., Hedman, U., Jakuba, M., Kunz, C., Larsson, B., Liljebladh, B., Linder, J., Murphy, C., Nakamura, K., Pontbriand, C., Sato, T., Schlindwein, V., Strane, C., Tausendfreund, M., Upchurch, L., Willis, C., and Winsor, P. (2007). Scientific scope and summary of the Arctic Gakkel vents (AGAVE) expedition. In EOS, Transactions of the AGU, volume 88.

Stojanovic, M. (1996). Recent advances in high-speed underwater acoustic communications. IEEE Journal of Oceanic Engineering, 21(2):125-136.

Stojanovic, M. (2007). On the relationship between capacity and distance in an underwater acoustic communication channel. SIGMOBILE Mobile Computing and Communications Review, 11(4):34-43. 
Thorleifson, J., Davies, T., Black, M., Hopkin, D., and Verrall, R. (1997). The Theseus autonomous underwater vehicle: A Canadian success story. In Proceedings of the IEEE/MTS Oceans Conference and Exhibition, pages 1001-1008.

Turtle, E. P. and Pierazzo, E. (2001). Thickness of a Europan ice shell from impact crater simulations. Science, 294(5545):1326-1328. 